\title{
POR ONDE OS AFRICANOS CHEGARAM: O CAIS DO VALONGO E A INSIITUCIONALLZACÃOO DA MEMÓRIA DO TRÁFICO NEGREIRO NA REGIÃOO PORTUÁRIA DO RIO DE JANEIRO*
}

\author{
Simone Vassallo** \\ Universidade Cândido Mendes - Brasil
}

\section{André Cicalo ${ }^{* * *}$ \\ King's College London - Reino Unido}

Resumo: Este artigo tem por objeto o processo de institucionalização e patrimonialização da memória da diáspora africana na região portuária do Rio de Janeiro, através de uma reflexão sobre as ações e representações em torno do sítio arqueológico Cais do Valongo, antigo cais de desembarque de cativos africanos. Procuramos compreender como, num determinado contexto, alguns grupos de atores chegam a consensos que favorecem a institucionalização da memória da diáspora africana na região. Acreditamos que a patrimonialização do Cais do Valongo ocorre na interseção de dois fenômenos entrelaçados: a) o reconhecimento do multiculturalismo e da diversidade étnico-racial no Brasil; b) os grandes projetos de revitalização urbana assumidos pelas municipalidades. Concentramos a observação em três grupos de atores: lideranças do movimento negro, pesquisadores acadêmicos e representantes do poder público municipal. Procuramos compreender como, juntos, eles produzem a localidade do Cais do Valongo como principal referência da chegada de africanos escravizados no país.

Palavras-chave: diáspora africana, multiculturalismo, patrimonialização, revitalização urbana.

\footnotetext{
* Parte do trabalho que levou a esta publicação recebeu financiamento do People Programme (Marie Curie Actions) da European Union's Seventh Framework Programme (FP7/2007-2013) sob o acordo de financiamento REA $n^{\circ}$ PIOF-GA-2012-327465. A pesquisa que viabilizou o artigo também recebeu financiamento da Faperj, edital Apoio às Humanidades.

** Contato: simonevassallo@iuperj.br.

*** Marie Curie Research Fellow. Contato: andre.cicalo@gmail.com.
} 


\begin{abstract}
This article aims to discuss the institutionalization of the heritage of the African diaspora in the port region of Rio de Janeiro, by reflecting on the actions and meanings developed around the archaeological findings of a slave trade pier, the Valongo Pier. We show how, in a given historic and sociopolitical context, relationships enacted by some institutionalized groups of actors end up converging, recognizing the importance of the institutionalization of this memory. We believe that this process occurs in the intersection of two phenomena: a) the recognition of the multiculturalism and the ethnic-racial diversity in Brazil; b) the urban processes of revitalization lead by the city council. We concentrate our analyses in three main groups of actors: black movement activists, academic searchers and municipality's representatives. We try to show how these actors produce the site of Valongo Pier as the main material reference of the slave trade diaspora in the country.
\end{abstract}

Keywords: African diaspora, heritage building, multiculturalism, urban revitalization.

\title{
Introduç̃o
}

No dia 20 de novembro de 2013, Dia da Consciência Negra, uma delegação de funcionários da Organização das Nações Unidas para a Educação, a Ciência e a Cultura (Unesco), liderados pelo diretor do projeto Rota do Escravo, Ali Moussa Iye, diante de autoridades da Prefeitura do Rio de Janeiro, de lideranças do movimento negro e de pesquisadores universitários, colocava uma placa comemorativa no sítio arqueológico Cais do Valongo, reconhecendo-o como um importante lugar de memória da diáspora africana. O local, desenterrado em 2011, durante as obras do ambicioso projeto Porto Maravilha de revitalização da região portuária, representaria o lugar por onde desembarcaram ao menos 500 mil africanos escravizados até a primeira metade do século XIX no Rio de Janeiro. No evento, foi enfatizado pelos participantes que o Cais do Valongo representa um testemunho da diáspora africana sem igual no mundo, tanto por seu bom estado de preservação e quantidade de escravizados recebidos como por representar a continuidade física e simbólica dos locais de partida já identificados e tombados pela Unesco na costa africana. Por esse motivo, foi unanimemente proposto que o lugar deveria ser candidatado a patrimônio da humanidade. As falas de delegados da Unesco então presentes sublinharam que o sítio possui um potencial pedagógico e turístico inestimável e que daqui a 20 anos poderá ser tanto ou mais visitado que o Corcovado e o Pão de Açúcar. 
O presente artigo tem por objeto o processo de institucionalização e patrimonialização de lugares de importância histórica e simbólica que remetem à memória da escravidão na área portuária do Rio de Janeiro, através da reflexão sobre as ações e representações que vêm ocorrendo recentemente em torno do Cais do Valongo. A partir do acontecimento acima, levantamos as seguintes questões: como um local desenterrado durante obras de revitalização se transforma progressivamente num dos maiores símbolos do tráfico transatlântico de cativos africanos e de sua chegada no Brasil? Quais os principais atores envolvidos nesse processo? Que contexto favorece a elaboração dessas memórias e por que justamente agora? Quais as novas realidades criadas a partir dessas dinâmicas? Procuramos compreender como é que, através de relações de conflito e negociação, num determinado contexto histórico e sociopolítico, alguns grupos de atores chegam a consensos em torno da institucionalização da memória da diáspora africana na região portuária. Acreditamos que, através dessas ações, esses atores conseguem trazer a memória do tráfico negreiro para a pauta do projeto de revitalização, que até então não previa a sua institucionalização.

Nosso ponto de vista é que a patrimonialização do Cais do Valongo ocorre na interseção de dois fenômenos, que se encontram aqui entrelaçados, e que têm ganhado espaço na sociedade brasileira nos últimos anos: a) a gradual afirmação do multiculturalismo e da diversidade étnico-racial; b) os grandes projetos de revitalização urbana assumidos pelas municipalidades com o apoio do capital privado. Esse é o contexto histórico e sociopolítico no qual se realiza a institucionalização da memória da diáspora africana. Ele se dá através das ações conjugadas de três principais grupos de atores, sobre os quais concentramos a observação: lideranças do movimento negro, pesquisadores acadêmicos (sobretudo arqueólogos, historiadores e antropólogos) e representantes do poder público municipal.

A memória da diáspora africana tem sido pesquisada especialmente nos lugares de partida do continente africano, onde historiadores e antropólogos têm dedicado grande espaço à reflexão sobre a construção de lugares de memória e à sua apropriação pelas comunidades locais (Araujo, 2010; Landry, 2011; Schramm, 2004). Na Europa, países como Inglaterra e Holanda têm uma trajetória consolidada na discussão pública sobre as injustiças cometidas durante a escravidão, promovendo a criação de monumentos que resgatem de forma crítica a memória do tráfico negreiro (Chivallon, 2001; Nimako; 
Willemsen, 2011). Nas Américas, os Estados Unidos ocupam um lugar chave tanto em termos de pesquisas quanto de políticas públicas, graças à presença de pesquisadores negros engajados como Michael Blakey (2010) e Theresa Singleton (Singleton; Torres de Souza, 2009). Na América Latina e no Brasil, para alguns autores, o reconhecimento da memória do tráfico negreiro teria começado de forma tardia. Isso dependeria de certa reticência histórica desses países em relação ao seu passado escravista e da ênfase dada a conceitos de identidade nacional baseados na ideia de mestiçagem e democracia racial (Trouillot, 1995, p. 18). A demora desse processo explicaria também a relativa exiguidade de estudos sobre patrimonialização da memória da escravidão atlântica no Brasil.

Nesse artigo, procuramos problematizar a "emergência” dessas memórias traumáticas que ressignificam a escravidão negra, propondo que elas se constroem a partir das múltiplas relações entre o local e o global, que fazem com que ideias desenvolvidas fora sejam reapropriadas e ressignificadas a nível local e assim incorporadas às lutas de atores sociais espacialmente localizados. Com isso, buscamos trazer mais elementos para a questão da demora nesse processo. Por que só agora a memória do tráfico negreiro transatlântico tornou-se alvo de inúmeras ações de setores da sociedade civil e da municipalidade do Rio de Janeiro?

Pela sua evocação de fluidez e dispersão, o conceito da diáspora tem ocupado um espaço importante nos estudos pós-modernos e antiessencialistas, como enfatizado nos trabalhos de James Clifford (1994) e Paul Gilroy (2001). Esses autores evidenciam como o uso do conceito, criado inicialmente em referência à dispersão da comunidade judaica, se estendeu gradualmente para outras comunidades. Entre outros usos, a ideia tem sido aplicada amplamente para descrever o processo de remoção forçada de cativos africanos durante o tráfico negreiro e a recomposição, híbrida e heterogênea, dos seus laços políticos e sociais em outros contextos geográficos. Esse novo conceito de movimentos diaspóricos não se caracteriza necessariamente por um desejo ou um projeto de volta a uma terra de origem, como na tradição judaico-sionista (Safran, 1991). Diáspora pode se entender hoje, de forma mais ampla, como algo em oposição a fronteiras, enraizamento e Estado-nação (Clifford, 1994, p. 308). Além disso, o conceito se expressa fortemente através de uma "história compartilhada de deslocamento, sofrimento, adaptação e resistência” (Clifford, 1994, p. 306, tradução nossa). Dada essa leitura, como Clifford 
(1994, p. 308, tradução nossa) observa, a diáspora "não é somente um significador de movimento e transnacionalismo, mas também de batalhas políticas que definem o âmbito local” de uma comunidade no contexto do seu deslocamento histórico. A ênfase na dimensão ao mesmo tempo localizada e política do conceito de diáspora nos ajuda a iluminar as múltiplas dinâmicas de negociação e conflito, que envolvem representantes do Estado, ativistas negros e pesquisadores, através das quais ocorre a institucionalização da memória do tráfico negreiro transatlântico na região portuária, tendo o Cais do Valongo como sua principal referência.

As ideias de Michael Pollak (1992) sobre o processo de enquadramento da memória podem contribuir para o entendimento da institucionalização progressiva da memória atribuída atualmente ao Cais do Valongo e dos conflitos que a perpassam. O autor retoma a noção de quadros sociais da memória, proposta por Maurice Halbwachs nas primeiras décadas do século XX, mas introduz uma perspectiva processual. Pollak (1992) desnaturaliza a relação entre uma determinada coletividade e as memórias que esta reivindica para si e sugere que as memórias são progressivamente construídas, através de relações de negociação e conflito. Elas encarnam valores disputados por indivíduos e organizações, dotados de diferentes interesses e pontos de vista. No caso das memórias coletivas, ocorrem disputas em torno de como o passado deve ser interpretado e quem tem legitimidade para fazê-lo. Esse processo se inscreve no tempo, na duração, através de um árduo e lento trabalho de valorização e hierarquização de datas, personagens e acontecimentos, que requer grande investimento por parte daqueles que o fazem. Através dessas tensões e negociações entre diferentes grupos de atores e perspectivas, produz-se o trabalho de enquadramento da memória, pelo qual uma determinada perspectiva sobre o passado, progressivamente construída, se torna vitoriosa e hegemônica e, assim, se institucionaliza.

Daniel Fabre (2009) traz elementos para o aprofundamento da dimensão construída e conflitiva da memória ao refletir sobre os patrimônios na contemporaneidade, sujeitos a intensos processos de turismo de massa. $\mathrm{O}$ autor aponta para as transformações nos usos e representações em torno de um monumento histórico ao longo do tempo. Para ele, a presença de um monumento, em si, não é uma garantia da perenidade da memória que evoca. É preciso que haja um trabalho permanente de gestores, guias turísticos e outros para que sua memória seja lembrada. De acordo com Fabre, os monumentos são 
objetos ventríloquos, ou seja, possuem vozes e significados que variam em função de quem os observa: moradores, turistas, gestores, entre outros atores, não compartilham necessariamente os mesmos entendimentos a seu respeito. As transformações de sentido também se inscrevem na duração: ao longo do tempo, os monumentos emitem histórias circunstanciais, verdades datadas que se transformam progressivamente.

Por trás da polifonia dos monumentos, o processo de patrimonialização pode levar ao que Fabre (2009) chama de unanimidade negociada, ou seja, a produção de um consenso em torno de certos significados e ações. Essa ideia nos parece importante por apontar para as inúmeras disputas que estão por trás das aparentes convergências na construção de memórias. Ela implica uma suspensão (provisória) dos conflitos e relações de força que estão em jogo, em prol da fraternização em torno do monumento. Tal fenômeno produz uma conversão monumental, que traz para um determinado local ou objeto novos significados e práticas, ao mesmo tempo em que introduz novos atores e disputas. Para o autor, essa unanimidade ocorre particularmente em locais que aspiram ao título de patrimônio da humanidade pela Unesco, já que a suspensão das polêmicas é uma das condições de seleção do dossiê. Em nossas reflexões sobre a patrimonialização do Cais do Valongo e a memória diaspórica que ele evoca, propomo-nos a pensar como um determinado consenso é progressivamente produzido em torno do sítio arqueológico, bem como a polifonia e os conflitos de perspectivas e interesses que perpassam esse processo.

Nesse artigo, propomo-nos a retomar a ideia das histórias circunstanciais e verdades datadas que giram em torno de um monumento. De modo provocador, sugerimos que as atuais memórias evocadas para o cais são também circunstanciais e datadas. Não por uma intenção iconoclasta de denunciar uma suposta inverdade, mas sim para realçar a nossa proposição central, a de que as atuais representações do Valongo estão profundamente articuladas a certos contextos contemporâneos nacionais, com entrelaçamentos transnacionais, sem os quais elas dificilmente poderiam emergir. No caso do recém-desenterrado sítio arqueológico, o que podemos observar é o processo inicial de construção de um determinado significado, cujas ressignificações futuras ainda não podemos prever.

Arjun Appadurai (1996) complexifica ainda mais a nossa perspectiva ao levar em conta o contexto mais amplo que orienta as ações humanas, bem como a dimensão performática dessas ações, que produzem novas realidades. 
Sua análise atribui uma importância fundamental ao contexto, num duplo sentido. Por um lado, trata-se do quadro de referências no qual as novas ações e representações podem se desenvolver. Mas, por outro, essas mesmas ideias e práticas transformam progressivamente os contextos. Para ele, "é assim que os sujeitos da história se tornam sujeitos históricos” (Appadurai, 1996, p. 185, tradução nossa).

Appadurai critica a ideia de uma reprodução mecânica da localidade. Para o autor, os grupos sociais produzem suas localidades através de um trabalho árduo e regular para a sua manutenção e reafirmação. Para tanto, utilizam técnicas sociais, ou seja, ritos dotados de um caráter ativo, intencional e produtor de novas realidades, que atribuem nomes, características, valores e significados aos locais a que se referem. Ao fazê-lo, produzem também os seus próprios "nativos", aqueles que legitimamente afirmam o seu pertencimento e reivindicam a sua herança. Trazendo a reflexão para a contemporaneidade, Appadurai (1996) assinala que esses processos envolvem uma coprodução que resulta de negociações entre diferentes grupos de atores, como os que reivindicam a autoctonia, representantes do Estado e organizações transnacionais. Assim, o autor desnaturaliza as relações entre uma localidade e seus supostos “nativos” e aponta para a pluralidade de atores envolvidos nessa construção. Através das ideias de Appadurai, propomos-nos a pensar o processo de patrimonialização do Cais do Valongo como coproduzido por diferentes grupos de atores, como ativistas negros, representantes do Estado e pesquisadores universitários. Essa coprodução é fruto de um determinado contexto histórico e sociopolítico mais amplo, dentro do qual se relacionam atores locais e transnacionais, mas ela também cria uma nova realidade: a localidade Cais do Valongo como uma referência fundamental à memória da diáspora africana e a sua inclusão no projeto Porto Maravilha de revitalização.

\section{A construcão de um consenso: 0 Cais do Valongo e a memória da diáspora africana no porto}

Em 2009, um grande projeto de intervenção urbanística, o Porto Maravilha, foi assinado pela Prefeitura do Rio de Janeiro prometendo revitalizar uma área da cidade considerada fortemente abandonada pelo poder público: a região portuária. Os objetivos do projeto, administrado pela empresa 
de capital misto Companhia de Desenvolvimento Urbano da Região Portuária (CDURP), se articulavam em vários eixos. Dentre eles, o melhoramento da infraestrutura urbana básica (vias, saneamento, iluminação), a criação de áreas de negócios, a oferta turística e de lazer. Tal projeto ganhava relevância no contexto dos grandes eventos que a cidade iria em breve abrigar - a Copa do Mundo, em 2014, e os Jogos Olímpicos, em 2016 - e obtinha forte apoio político e financeiro dos governos federal e estadual. O Porto Maravilha se inspirava num projeto mais modesto de reforma da região portuária desenvolvido ao longo da dupla gestão do prefeito anterior, entre 2001 e 2009. Desde então, grupos de moradores, organizações culturais e coletivos da sociedade civil começaram a se mobilizar, receosos dos efeitos gentrificadores da revitalização, num processo que se intensificou com a proximidade das obras (Cicalo, 2013; Costa, 2010; Guimarães, 2011; Vassallo, 2012, 2014).

Uns poucos intelectuais se mostraram particularmente inquietos com o patrimônio histórico da região, cujo legado afrodescendente tinha sido pouco valorizado no século anterior e corria o risco de ser aniquilado pelo processo de modernização. Dentre eles, o historiador Carlos Eugênio Líbano Soares e a arqueóloga Tânia Andrade Lima, pesquisadores e professores universitários, visavam resgatar arqueologicamente a antiga área de chegada de cativos africanos, o Cais do Valongo e, para tanto, solicitaram formalmente ao Instituto do Patrimônio Histórico e Artístico Nacional (Iphan) a autorização para a sua escavação. O contexto das obras de revitalização foi fundamental para que o cais pudesse ser desenterrado. De acordo com Tânia, "não tínhamos a verba para fazer a escavação, romper uma rua, quebrar camada de asfalto, só o poder público pode fazer isso" (entrevista, junho de 2013).

Desde os anos 1990, Carlos Eugênio se dedica aos estudos da escravidão urbana no Rio de Janeiro e concentra boa parte de suas análises na região portuária (Soares, 1994, 1998, 2011). Seus trabalhos vêm contribuindo para a consolidação do imaginário dessa região como um lugar de memória afrodescendente. Em 2010, Carlos Eugênio sensibilizou Tânia Andrade Lima a respeito da importância histórica do cais, o que resultou na solicitação formal da sua escavação. Tânia também teve um outro modo de participação fundamental: foi ela a contratada pela prefeitura para fazer o monitoramento arqueológico da primeira fase das obras do Porto Maravilha, o que deu uma grande visibilidade aos seus entendimentos sobre o cais e possibilidades de diálogo direto com os representantes dos órgãos de proteção patrimonial e das obras 
do projeto de revitalização. De acordo com Tânia Lima e Carlos Eugênio Soares, a área do Valongo teria recebido ao menos meio milhão de escravos entre fins do século XVIII - quando o desembarque de cativos africanos foi transferido da Praça XV para o Valongo - e 1831 - quando o tráfico negreiro transatlântico foi formalmente proibido. Para os pesquisadores, essa área do cais representa o maior porto negreiro das Américas e constitui um lugar emblemático da diáspora africana em nível internacional. Em 1843, o local teria sido remodelado e transformado no Cais da Imperatriz, com o intuito de receber a princesa Tereza Cristina das duas Sicílias, que desembarcava da Europa recém-casada com o imperador D. Pedro II. A área toda foi aterrada na primeira década do século XX, no âmbito das reformas urbanísticas promovidas pelo então prefeito Pereira Passos, dando lugar à praça Jornal do Comércio, localizada na atual avenida Barão de Tefé. O projeto Porto Maravilha, inicialmente sem grande interesse por esse passado afrodescendente, previa grandes obras na rede de esgoto e de eletricidade do local onde se encontravam os vestígios soterrados do cais, bem como a sua transformação numa importante via pública.

Em março de 2011, quando a área foi finalmente escavada a pedido dos pesquisadores, o Cais da Imperatriz e o Cais do Valongo foram encontrados em bom estado de preservação, um acima do outro com um desnível de cerca de 60 centímetros. Durante a escavação, objetos ligados ao cotidiano dos afrodescendentes e outros artefatos foram também achados e coletados para estudo. Em decorrência, Tânia Andrade Lima assinalou à prefeitura a importância histórica do lugar, solicitando a sua preservação. Em visita ao local, e diante da presença da mídia e de outras autoridades da municipalidade, o prefeito Eduardo Paes deu disposições imediatas de preservação da área, vendo ali as "ruinas romanas” do Rio de Janeiro, algo que reescreveria a história da cidade.

Tânia Lima era fortemente influenciada pela perspectiva que emergiu nos anos 1980, segundo a qual a arqueologia não deve mais favorecer os interesses nacionalistas e hegemônicos do Estado, mas sim as lutas políticas de empoderamento dos grupos minoritários que se veem como herdeiros de sítios arqueológicos (Silverman, 2011). A partir de então, desenvolve-se uma arqueologia engajada, que reconhece seu papel histórico e social e que não mais se vê como "uma província exclusiva dos europeus brancos e dos estratos superiores da sociedade, excludente, hierárquica e dotada de um conhecimento que 
marginaliza a arqueologia multivocal das periferias” (Silverman, 2011, p. 3, tradução nossa). É nesse contexto que a arqueologia afro-americana cresce exponencialmente nos EUA. Tânia se inspirava na atuação do bioarqueólogo norte-americano Michael Blakey junto ao African Burial Ground de Nova York. ${ }^{1}$ Para ele, a pesquisa em sítios arqueológicos só pode ocorrer com a participação ativa do que chama de "comunidade de descendentes" e deve contribuir para as suas lutas por reconhecimento (Blakey, 2010). Assim, ao encontrar os dois cais superpostos, Tânia optou por privilegiar o do Valongo, já que, no seu entender, o da Imperatriz representava a história da nobreza, que já era suficientemente lembrada na historiografia nacional. Mais do que isso, ela viu na sobreposição dos dois cais a expressão das relações de dominação de brancos sobre negros que perpassa toda a formação da sociedade brasileira. Segundo a arqueóloga, houve uma prática deliberada de silenciamento da história do Cais do Valongo:

Os escravos foram esquecidos e, mais do que isso, eles foram deliberadamente apagados ao ser colocado sobre o Cais do Valongo o Cais da Imperatriz, num processo de superposição fortemente simbólico. Sobre a escória humana trazida da África foi colocada uma princesa europeia, uma Bourbon, a Princesa das Duas Sicílias. Ela pisando sobre os negros. ${ }^{2}$

As declarações de Tânia Lima circularam tanto na mídia nacional e internacional quanto em eventos científicos no país e no exterior. Assim, essas interpretações dos acontecimentos se difundiram amplamente: o Valongo como o principal local de desembarque de cativos africanos nas Américas e a superposição dos cais como prova e símbolo da dominação racial existente no país.

Acreditando na importância da participação da "comunidade de descendentes”, a arqueóloga e o historiador começaram a informar e sensibilizar as organizações do movimento negro, cuja atitude acerca do tráfico negreiro tinha sido ambígua até então. Num gesto altamente significativo, Tânia Lima convidou importantes lideranças negras para visitar o cais e os contêineres

\footnotetext{
1 Local onde, no início dos anos 1990, foram encontradas ossadas de escravizados africanos e que se tornou hoje um Monumento Nacional Americano.

2 Cf. http://www.youtube.com/watch?v=RQP_8pn0U3E.
} 
que abrigavam os artefatos encontrados nas escavações. Ali, a arqueóloga lhes deu longas explicações sobre a história do sítio e dos objetos encontrados nas proximidades.

A partir de então, representantes do movimento negro começaram a se reunir e a formular os seus próprios entendimentos acerca do cais. As organizações envolvidas eram sobretudo as dos setores governamentais, como o Conselho Municipal de Defesa dos Direitos do Negro (Comdedine), a Superintendência de Promoção da Igualdade Racial (Supir), a Coordenadoria Especial de Políticas Pró-Igualdade Racial (Ceppir), a Fundação Palmares e o Conselho Estadual de Defesa dos Direitos do Negro (Cedine). Para eles, esse sítio não só era um símbolo da dominação racial, como também uma referência fundamental em termos da sua própria ancestralidade. Um documento elaborado na ocasião declarava que "por esse cais passou boa parte dos antepassados que deram origem ao maior grupo étnico do Brasil contemporâneo. Portanto, a ancestralidade de mais da metade da população brasileira tem ali uma forte referência simbólica” (Proposta..., 2011). Para muitos ativistas negros, foi também por ali que, junto com os africanos, desembarcaram objetos, práticas e crenças que deram origem à cultura e às religiões afrodescendentes. O cais adquire então uma dimensão mítica que explica a origem dos povos, das culturas e das religiões afro-brasileiras, muito bem expressa nas palavras da ialorixá Mãe Edelzuita de Oxaguian, convidada por ativistas negros e pesquisadores para opinar sobre a relevância dos achados arqueológicos: "aqui é a raiz de tudo".

Essas lideranças negras reivindicavam uma participação nos rumos do sítio arqueológico recém-descoberto. A partir de reuniões desses ativistas com o então subsecretário de Patrimônio Cultural, Washington Fajardo, foram encaminhadas medidas ao prefeito que resultaram na promulgação do Decreto $n^{\circ}$ 34803, de novembro de 2011. Este determinava a criação do Circuito Histórico e Arqueológico de Celebração da Herança Africana na Zona Portuária e de um Grupo de Trabalho Curatorial, cujas recomendações deveriam integrar o processo de construção da memória africana e afrodescendente na localidade. O circuito procura evidenciar o vasto complexo escravagista da região e, tendo o Cais do Valongo como epicentro, é também composto pelos seguintes pontos: o Cemitério dos Pretos Novos, a Pedra do Sal, o Jardim Suspenso do Valongo, o Largo do Depósito e o Centro Cultural 
José Bonifácio. ${ }^{3} \mathrm{O}$ Grupo de Trabalho incluía representantes da Subsecretaria de Patrimônio Cultural, ${ }^{4}$ da CDURP e do movimento negro, prestigiosas mães de santo, pesquisadores acadêmicos ${ }^{5}$ e agentes culturais da região portuária. Ao final dos encontros foi elaborada uma Carta de Recomendações, assinada por todos os integrantes do Grupo de Trabalho, que revela o consenso em torno da "importância histórica e cultural da Região Portuária do Rio de Janeiro para a compreensão do processo da Diáspora Africana e da formação da sociedade brasileira” (Carta..., 2012). Também foi consensual a determinação de que todos os anos deveria haver uma lavagem religiosa no cais para apaziguar o sofrimento dos que ali desembarcaram. Aos poucos, além das lavagens, lideranças do movimento negro e da cultura afro-brasileira começaram a realizar, junto ao cais, rodas de capoeira, homenagens póstumas a importantes militantes e ancestrais e outras formas de celebração, geralmente com algum patrocínio da prefeitura, através da companhia responsável pelo projeto de revitalização (Vassallo, 2012).

Assim, pela ação conjugada desses grupos de atores, construiu-se progressivamente um consenso em torno da importância fundamental do Cais do Valongo para a memória da diáspora africana e da necessidade da sua valorização pública. Iniciou-se um trabalho de enquadramento dessa memória, nos termos de Michael Pollak (1992), no qual um determinado entendimento do cais se tornou dominante e se institucionalizou. A atuação conjunta desses agentes realizou uma "conversão monumental” (Fabre, 2009) que trouxe novas práticas e significados para o sítio, que passou a ser delimitado, qualificado e administrado de novas maneiras. Produziu-se uma localidade, o Cais do Valongo como território afrodescendente e como lugar de memória da diáspora africana, bem como os seus próprios nativos, aqueles que reivindicam a herança afrodescendente.

\footnotetext{
3 Respectivamente: local onde eram enterrados os africanos que morriam próximos ao momento do desembarque; local de referência fundamental para a origem do samba; locais que outrora abrigaram os mercados de escravos; centro cultural destinado à cultura afro-brasileira.

4 Transformada em 2012 no Instituto Rio Patrimônio da Humanidade, quando a cidade foi declarada patrimônio da humanidade pela Unesco no quesito "Paisagem Cultural”.

5 Dentre eles, Tânia Andrade Lima, Carlos Eugênio Soares e o intelectual e ex-diplomata Alberto da Costa e Silva, grande referência em história africana no Brasil.
} 


\section{0 local e o global no Valongo}

A movimentação descrita acima em torno do Cais do Valongo se deve em boa medida ao fato de que, logo que foi desenterrado e que começou a se difundir o seu entendimento como principal local de desembarque de africanos no país e nas Américas, houve um outro consenso: os representantes do governo, do movimento negro e da sociedade civil envolvidos no processo concordavam que o cais deveria ser reconhecido como patrimônio da humanidade e que as providências para tal deveriam começar a ser tomadas. No mesmo momento em que o cais foi desenterrado, e contribuindo amplamente para a institucionalização da sua memória, ocorreu o que o antropólogo e professor da UFF (Universidade Federal Fluminense), Milton Guran, qualificou como uma "conspiração do bem” (entrevista, junho de 2014) e que passamos a descrever agora.

Em 2010, Guran assumiu o cargo de representante brasileiro do Conselho Científico Internacional do Projeto Rota do Escravo (RDE), promovido pela Unesco. Fundado em 1994, por ocasião das celebrações dos 500 anos do descobrimento das Américas e da onda de eventos que se propunham a uma reflexão crítica sobre essa “descoberta”, o RDE tinha por objetivo a criação de lugares de memória do tráfico negreiro nos portos africanos de embarque de cativos e, posteriormente, em outras regiões do mundo, através da conservação de sítios históricos e do estímulo à construção de monumentos. Para tanto, fundou um comitê científico que reúne mais de 20 países, solicitando a cada um a realização de um inventário nacional dos lugares de memória da diáspora africana. Como principal continente de chegada desses cativos, as Américas representavam um lugar-chave e receberam grande atenção. Como parte de suas atribuições, Guran desenvolveu o inventário dos cem lugares de memória do tráfico atlântico de escravos e da história dos africanos escravizados no Brasil, oficialmente divulgado em meados de 2012.

Desde a sua criação, pouco depois do fim da Segunda Guerra Mundial, a Unesco se empenha no combate ao racismo e à noção biologizante de raça (Maio, 2010), bem como na promoção da diversidade cultural. A criação do RDE se insere nessa proposta, pois visa a sensibilização e a reflexão sobre o que foi a escravidão e os seus desdobramentos passados e presentes. 
Em analogia com o holocausto judeu, a Unesco classifica tal ato como um crime contra a humanidade.

Como desdobramento desse processo, os locais contemplados pelo RDE devem se tornar alvo de projetos de turismo étnico e de memória da diáspora, visando a sua sustentabilidade econômica. Os mais emblemáticos foram reconhecidos pela própria Unesco como patrimônios da humanidade e são alvos de visitações turísticas, sobretudo de afro-americanos, com visitas guiadas que provocam fortes emoções e uma experiência multissensorial de reviver o passado dos africanos capturados, que muitos consideram seus ancestrais (Araujo, 2007, 2009; Landry, 2011).

Foi em pleno processo de realização do inventário do RDE no Brasil, em 2011, que o Cais do Valongo foi desenterrado e que Milton Guran tomou ciência do fato, pela imprensa, atribuindo-lhe uma importância-chave. Rapidamente ficou claro que o cais deveria se tornar o centro dos locais inventariados:

Eu vi que o Valongo era o farol, a joia da coroa do inventário, porque não existe nada fora da África que tenha a força simbólica e a materialidade desse cais. Tudo foi destruído [...]. E o cais está ali e essas pedras foram pisadas por talvez 1 milhão de escravos. (Entrevista, junho de 2014).

Assim, o cais adquire uma dimensão única, autêntica, "o maior monumento da diáspora africana fora da África”, prossegue Guran. Através dessas interpretações, a força simbólica do cais torna-se ainda maior e adquire um caráter de "revelação":

A presença africana foi apagada da nossa memória. Construíram um bairro inteiro, a Gamboa, em cima do local que conta essa história [...]. Estamos revelando, tirando os véus. (Entrevista, junho de 2014).

Não por acaso, Guran foi convidado para integrar o Grupo de Trabalho Curatorial do Circuito da Herança Africana.

A Fundação Cultural Palmares rapidamente percebeu a importância política do achado arqueológico e do seu reconhecimento como patrimônio da humanidade pela Unesco. Com esse intuito, organizou-se em Brasília o Seminário Internacional da Rota do Escravo, em agosto 2012, quando o Brasil pôde finalmente divulgar os resultados do seu Inventário dos lugares 
de memória do tráfico atlântico (Mattos; Abreu; Guran, 2014), na presença de inúmeros representantes da Unesco, políticos, lideranças do movimento negro, pesquisadores e líderes de religiões de matriz africana. Na abertura do evento, o presidente da Palmares oficializou a intenção de candidatar o Cais do Valongo como patrimônio cultural da humanidade. Nesse momento, foi lida uma carta do ex-presidente Luís Inácio Lula da Silva mencionando a importância desse cais nos lugares da nossa memória e declarando que "o resgate dessa história é fundamental para a superação do racismo" (Seminário..., 2012, p. 2). A ministra da Secretaria de Políticas de Promoção da Igualdade Racial, Luíza Bairros, também presente, afirmou que "é impossível passar pelo Cais do Valongo e não sair dali com uma sensação de compromisso com a história e a construção da cidadania no Brasil” (Seminário..., 2012, p. 5). Assim, articulava-se politicamente a candidatura do cais ao mesmo tempo em que se consagrava a sua íntima relação com a ideia de um dever histórico de reparação, tendo por referência o que ocorria nos outros locais do RDE. A discussão sobre o cais, até então mais restrita ao Rio de Janeiro, chegava às instâncias federais e internacionais.

Após esse evento, o interesse do prefeito pela patrimonialização do cais cresceu exponencialmente. Assim, fez questão de patrocinar a reunião estatutária do Comitê Científico Internacional do RDE, em novembro de 2013, percebendo a importância estratégica de sua realização na cidade. Esse encontro se concluiu com o episódio descrito no início do artigo, ou seja, a colocação da placa da Unesco no Cais do Valongo, consagrando-o como ponto oficial do RDE, na presença de autoridades, pesquisadores e setores governamentais do movimento negro. Nesse momento, foi mais uma vez ressaltada a importância da candidatura do Valongo como patrimônio da humanidade e o seu potencial turístico, que contribuirá para a fama internacional do Rio de Janeiro, já no centro das atenções mundiais por conta da Copa do Mundo de 2014 e dos Jogos Olímpicos de 2016. O dossiê do cais foi oficialmente encaminhado à Unesco em julho de 2014. Tais acontecimentos têm interesse estratégico para a atual prefeitura, empenhada em transformar a região portuária na nova imagem de marca da cidade através do projeto Porto Maravilha (Pio, 2012).

A participação dos representantes do governo federal e da Unesco no processo de patrimonialização do Cais do Valongo reforça e amplia o consenso 
em torno de seu significado e importância, e contribui ainda mais para a solidificação dessa memória. Ela nos mostra o quanto a produção de localidades, nos termos de Appadurai (1996), deve ser pensada na contemporaneidade a partir das densas redes que entrelaçam atores locais, representantes do Estado e órgãos transnacionais. Esse processo implica a ampliação dos entendimentos do sítio, que vão se tornando cada vez mais transnacionais. Para que uma candidatura a patrimônio da humanidade tenha mais chance de ser aceita, os postulantes devem sair das escalas locais e nacionais da história e ingressar na “instância do mundo inteiro e do horizonte humano em geral” (Fabre, 2009, p. 45, tradução nossa). O cais não é mais apenas uma referência em termos de ancestralidade afro-brasileira. Sua importância se transnacionaliza e ele se torna o mais eloquente símbolo do tráfico transatlântico de escravizados fora da África.

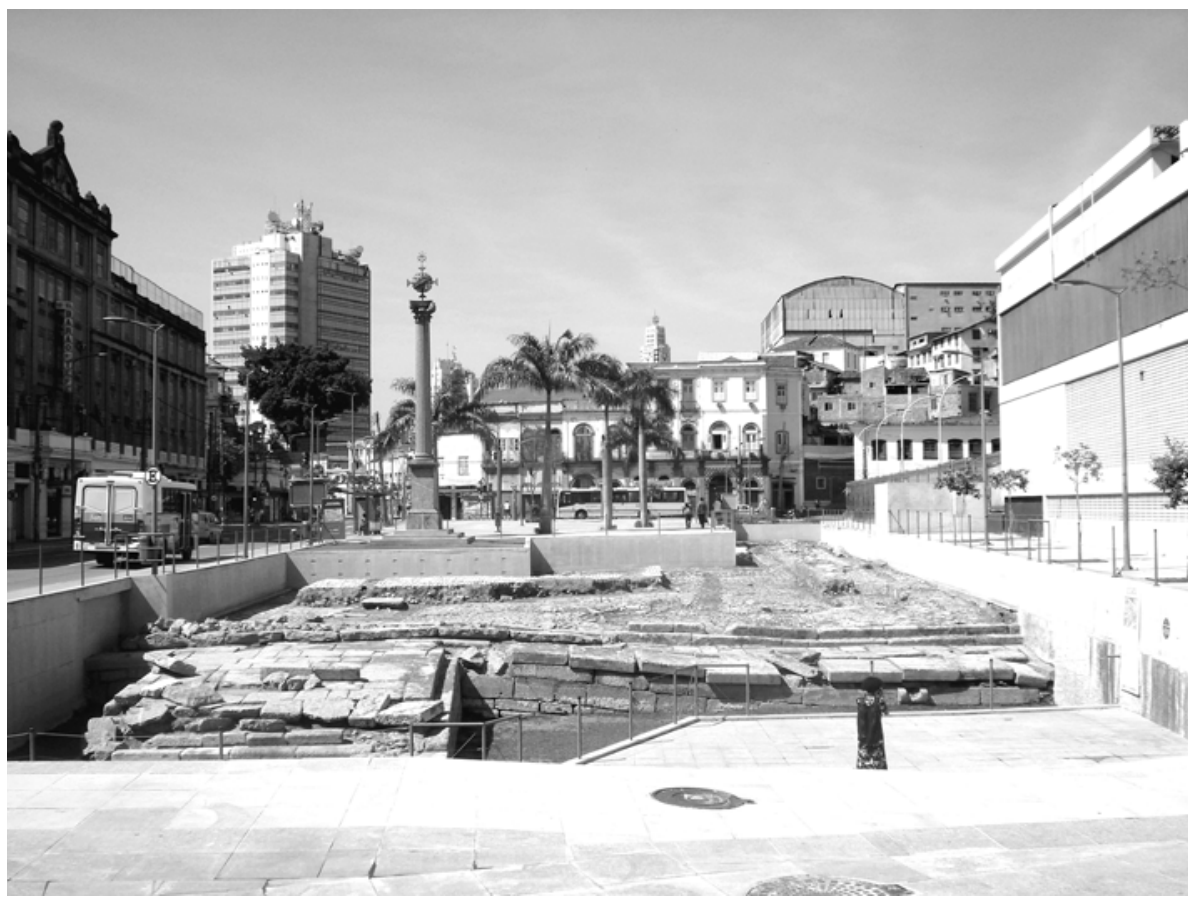

Figura 1. Vista do complexo monumental do Cais do Valongo (foto: André Cicalo). 


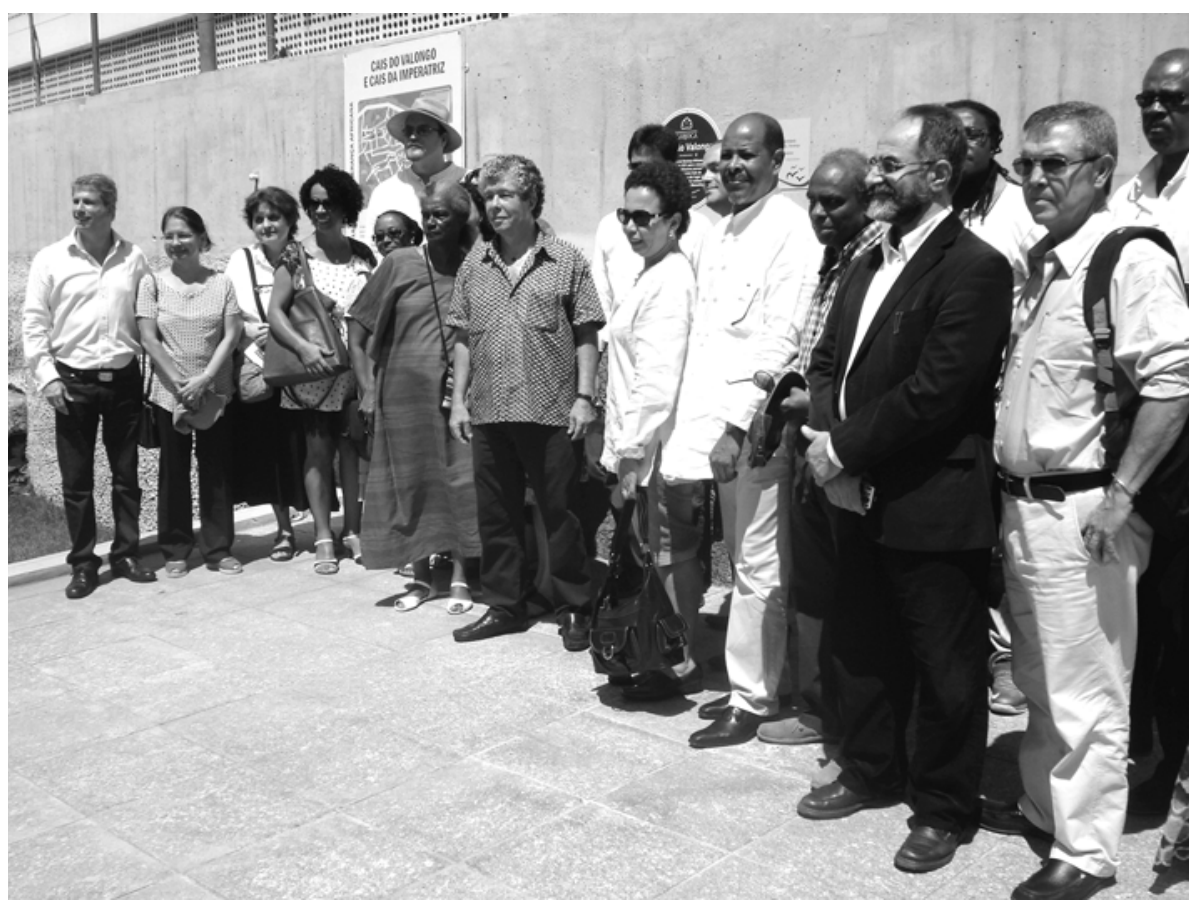

Figura 2. Representantes da Unesco, do movimento negro e da prefeitura logo após a colocação da placa de reconhecimento da Unesco no Cais do Valongo, em 20 de novembro de 2013 (foto: André Cicalo).

\section{Patrimônios: territórios em disputa}

Os consensos produzidos em torno do Cais do Valongo ocultam conflitos e divergências em torno de significados e práticas a eles relacionados. Inspirados nas ideias de Daniel Fabre (2009), acreditamos na existência de uma polifonia das experiências desse patrimônio, de uma pluralidade de pontos de vista que o transforma num território contestado e disputado.

Um exemplo significativo dessas divergências ocorreu imediatamente após o desenterramento do sítio arqueológico, quando a Subsecretaria de Patrimônio Cultural apresentou um projeto arquitetônico visando a sua exposição pública (Daflon, 2011). As organizações do movimento negro envolvidas no processo, lideradas pelo Comdedine protestaram nessa ocasião porque a elaboração do projeto institucional não envolvia os que eles consideravam 
serem os herdeiros e legítimos representantes dessa herança - os próprios afrodescendentes - e solicitavam a inclusão de um arquiteto negro. Essas queixas conseguiram deter o projeto inicial da prefeitura, que teve que ser refeito (Vassallo, 2012).

Foi também através das pressões dos ativistas negros sobre representantes da municipalidade que ocorreu o mencionado decreto municipal 34.803 (Rio de Janeiro, 2011), que instituiu o Circuito da Herança Africana e o Grupo de Trabalho Curatorial. Embora a Prefeitura tenha contemplado a participação de militantes negros, o decreto a limitava ao Comdedine. Essa participação só foi progressivamente ampliada através dos esforços dos integrantes desse órgão. Além disso, conferia-se ao Grupo Curatorial um poder meramente consultivo e não decisório. Também houve reclamação de instituições de promoção da cultura afro-brasileira por não terem sido oficialmente convidadas para participar das reuniões.

A cerimônia de inauguração do complexo arquitetônico do Cais do Valongo, organizada pela prefeitura, em julho de 2012, também foi alvo de discordâncias. Ela simbolizava o término da primeira fase das obras do projeto Porto Maravilha e contou com a presença do prefeito e do governador. O evento ocorria poucos meses antes das eleições municipais em que o então prefeito Eduardo Paes, mentor do projeto de revitalização, concorreria a um segundo mandato.

A festa teve início com uma grande lavagem do cais, realizada pelas prestigiosas Mãe Edelzuita de Oxaguian, Mãe Celina de Xangô e Mãe Beata de Iemanjá que, nesse momento, afirmaram mais uma vez a importância do local por onde chegaram tantos africanos. Depois da lavagem, houve um espetáculo teatral representando o desembarque da imperatriz Tereza Cristina, bem como encenações de samba e capoeira por dançarinos contratados. Em seguida, os participantes se dirigiram ao Jardim Suspenso do Valongo, recém-restaurado pela prefeitura, onde atores encenavam o antigo prefeito Pereira Passos, responsável pela grande reforma urbana do início do século XX, transmitindo cem anos depois o seu legado para o atual prefeito, responsável pelo atual projeto de revitalização.

Segundo uma importante liderança negra que não quis revelar seu nome na pesquisa, a prefeitura organizou uma festa para brancos, onde a presença dos afrodescendentes foi minimizada: 
O Cais do Valongo nesse dia não foi o centro da história. Os integrantes do grupo de teatro que foi contratado para o show da inauguração eram todos brancos... eles falaram da imperatriz, retrataram as músicas favoritas dela, todos vestidos de malandros, com camisa listrada e chapéu. Falaram o tempo inteiro da imperatriz, não do Cais [do Valongo]... Ficamos irritados. (Entrevista, setembro de 2013).

Dois anos depois, em julho de 2014, numa nova lavagem do Cais do Valongo, a presidente do Comdedine, Dulce Vasconcelos, afirmava publicamente o seu próprio entendimento sobre o sítio:

Isso aqui é um local sagrado não apenas para os afro-brasileiros, mas para todos aqueles que se revoltam com a escravidão do negro africano. Aqui é uma prova concreta do que aconteceu nos séculos XVII, XVIII e XIX e que ainda acontece hoje, no século XXI.

Já a prefeitura opta por um discurso mais homogeneizante, em que atenua a questão étnico-racial, afirmado num dos painéis da entrada do recém-criado Espaço Meu Porto Maravilha, bem ao lado do cais, em que expõe o projeto de revitalização aos visitantes, com alta tecnologia interativa:

Muito da herança africana e de imigrantes de todas as partes para a sociedade brasileira surgiu naquela região [do porto]. Palco de lutas sociais e manifestações culturais, lugar de grandes personagens, ela é um pedaço singular do Rio de Janeiro e do país. Suas ruas, seus casarios e suas igrejas contam muito sobre a formação e o amadurecimento de nossa identidade, sobre a formação do povo brasileiro.

Por trás do consenso em torno da singularidade do cais e da região portuária e da sua importância fundamental em termos identitários, encontramos divergências de pontos de vista. Se os militantes negros afirmam esses locais como patrimônios dos afrodescendentes, intimamente relacionados à sua própria ancestralidade e à discriminação racial, a prefeitura os equaciona a uma totalidade mais abrangente, a do povo brasileiro. Assim, se assemelha às tradicionais perspectivas patrimonializantes, de caráter nacionalista, que dissolvem as diferenças na totalidade abstrata da nação (Gonçalves, 2007; Handler, 1984) e silenciam as divergências e as relações de poder ali contidas. 
Criando ainda mais descontentamento durante a festa de inauguração, o prefeito não destinou um espaço oficial para o recebimento da Carta de Recomendações elaborada pelo Grupo Curatorial, que só chegou às suas mãos um ano depois. Os militantes negros se queixam do fato de que até hoje não receberam um retorno oficial sobre as sugestões contidas no documento.

Vários militantes também reclamaram do fato de que a maioria dos pontos que integram o Circuito da Herança Africana foi escolhida pelos representantes da prefeitura, e não por eles mesmos. A inclusão do Jardim Suspenso do Valongo, por exemplo, foi bastante questionada por ser um local construído no início do século XX, sem nenhuma relação direta com a memória africana ou com a escravidão. Ele teria sido incluído por ter sido totalmente restaurado no âmbito do projeto Porto Maravilha. Atenderia, portanto, aos anseios de promoção turística por parte da prefeitura, mas não às reivindicações do movimento negro. Para criar elos com a herança negra, os participantes do Grupo Curatorial passaram a descrevê-lo como o local onde, no passado, situava-se o mercado de escravos. Alguns militantes e representantes da cultura afro-brasileira também fizeram críticas ao excesso de importância atribuído ao cais, em detrimento de locais como o Cemitério dos Pretos Novos ou a Pedra do Sal.

Pouco depois da inauguração do Cais do Valongo, a prefeitura criou um roteiro de visitação turística da região portuária que inclui o cais, alguns pontos do Circuito da Herança Africana e localidades que fazem referência à herança portuguesa. Lideranças do movimento negro também tentam criar seus próprios roteiros de turismo étnico pela região, com ou sem o apoio da prefeitura, mas ainda não conseguiram implementá-los.

Por parte dos pesquisadores também houve conflitos. Tal como o que ocorre em pontos do RDE na costa africana (Araujo, 2007; Landry, 2011), a veracidade histórica do cais foi contestada por alguns historiadores. No entanto, essas acusações ainda não foram suficientes para frear o processo de institucionalização dessa memória e permanecem restritas a um pequeno grupo.

Por trás do consenso geral entre os atores mais diretamente envolvidos na patrimonialização do cais, temos uma "unanimidade negociada”. Ao mesmo tempo em que se evidenciam leituras e interesses diferenciados, produz-se uma suspensão das polêmicas em prol da fraternização (Fabre, 2009) em torno de um bem maior: o reconhecimento do Cais do Valongo como patrimônio da humanidade pela Unesco. Os principais grupos de atores envolvidos não compartilham os mesmos entendimentos sobre a herança africana na região 
portuária e nem sobre o papel de cada um deles no processo de patrimonialização. No entanto, as divergências são silenciadas em prol de um consenso, a promoção da memória da diáspora africana no porto e a necessidade de ações que a reconheçam e institucionalizem.

\section{"Conspiraccão do bem" ou transformação do contexto?}

A questão central que nos colocamos neste artigo é por que a patrimonialização da memória da diáspora africana na região portuária só vingou a partir de 2011. Está claro que o desenterramento do cais representou um acontecimento crucial para o desencadeamento do processo político e simbólico que descrevemos. Contudo, algumas condições materiais para a patrimonialização dessa memória já tinham se apresentado no passado, mas não foram adiante. Em 1996, por exemplo, foi descoberto acidentalmente o Cemitério dos Pretos Novos durante obras de infraestrutura numa habitação da região. O local teria abrigado os corpos dos cativos africanos que faleceram entre o momento do desembarque e o da sua comercialização, entre a década de 1770 e 1831, quando foi desativado atendendo à proibição do tráfico negreiro transatlântico (Honorato, 2008; Pereira, 2007; Tavares, 2012).

O achado impulsionou a criação de um grande seminário, em 2001, com a presença de pesquisadores brasileiros e estrangeiros. Esse mesmo evento destacou a necessidade de ampliar as escavações que evidenciassem o legado arqueológico da diáspora africana na região, o que não ocorreu. Nesse momento, já houve uma articulação de intelectuais, tendo à frente o historiador Carlos Eugênio Líbano Soares, visando o desenterramento do Cais do Valongo, sem sucesso. O mesmo Carlos Eugênio repetiria a iniciativa em 2011, dessa vez com êxito, desencadeando todo o processo que buscamos analisar. Como consequência da mobilização de pesquisadores, já em 2004, foi promulgado o decreto municipal n 24.088 (Rio de Janeiro, 2004), prevendo a criação de um roteiro turístico e a construção do Portal da Gamboa, que faria referência às portas de não retorno da costa africana. Nas duas últimas décadas, através dos projetos RDE da Unesco, esses locais se difundiram amplamente como símbolos do embarque dos cativos africanos para as Américas. O decreto ocorreu no contexto de um primeiro projeto de revitalização turística da região portuária, durante a gestão do prefeito Cesar Maia (2001-2008). Contudo, essa iniciativa naufragou: suas propostas não se realizaram e nem 
deixaram marcas. O Cemitério dos Pretos Novos ficou esquecido pela prefeitura, apesar das lutas do casal dono da área e de pesquisadores para chamar atenção de órgãos públicos. Acreditamos, portanto que, em 2011, houve um conjunto de circunstâncias favoráveis que influenciaram a atuação dos atores e a sua articulação, viabilizando o desenterramento do cais e a patrimonialização da memória do tráfico negreiro na localidade.

Portanto, não é suficiente a presença de certos atores para que a memória da diáspora africana seja valorizada. É necessário levar em conta o contexto e, nesse caso, o sistema ético-jurídico e político que prevalece na sociedade no momento histórico em que os atores individuais e institucionais operam e interagem. O antropólogo Milton Guran tem falado de uma série de coincidências que, “conspirando para o bem”, teriam levado à patrimonialização da memória da diáspora africana. Embora essa expressão seja eficaz, nos parece que as ações que têm levado à construção do Valongo como patrimônio diaspórico fazem parte de processos mais amplos, cuja convergência tem pouco a ver com o acaso.

Queremos apontar especificamente para os crescentes avanços em matéria de reconhecimento do multiculturalismo e da diversidade étnico-racial no Brasil e em diversas partes do mundo, que têm se difundido gradualmente nas últimas décadas. A partir dos anos 1980, com a redemocratização do país e a rearticulação do movimento negro, tanto as críticas à democracia racial como as lutas pelos direitos diferenciais das populações afro-brasileiras impulsionaram uma atenção crescente do Estado para a sua diversidade e as desigualdades étnico-raciais. Os anos 2000, em particular, constituíram um marco para o desenvolvimento de ações afirmativas em favor da população negra no Brasil. Dentre elas, podemos citar a implementação da lei 10.639, em 2003, que torna obrigatório o ensino da história e da cultura africana e afrodescendente nas escolas, a introdução das cotas universitárias para estudantes autodeclarados negros (Brasil, 2003), e a promulgação do Estatuto da Igualdade Racial, em 2010 (Cicalo, 2012). O primeiro passo dessa abertura é dado pela Constituição de 1988, que introduz a ideia de "direitos culturais", ao mesmo tempo em que reconhece a identidade de "remanescente de quilombo" e seus direitos territoriais (Arruti, 2006).

Esses acontecimentos não surgiram de forma isolada, mas sim através de diversas relações de âmbito transnacional. Já na Conferência de Durban, em 2001, o Brasil chamou a atenção mundial por admitir seu racismo e prometer 
medidas práticas para sua resolução. Há também a criação do Projeto Rota do Escravo pela Unesco, nos anos 1990, e as questões que suscita a respeito do tráfico negreiro, suas consequências sobre o persistente racismo nas Américas e na Europa e sobre o atual subdesenvolvimento do continente africano (Araujo, 2007). Tais processos se inserem num fenômeno mais amplo de emergência de um debate público sobre o passado colonial dos países europeus e sobre a memória da escravidão. Os discursos em torno dessas releituras do passado se articulam a pedidos de reparação financeira e simbólica para a África e a diáspora africana, e dão origem a uma nova forma de identificação, a dos que se consideram "descendentes de escravos" que, como tais, fazem reivindicações específicas (Araujo, 2007). Os novos entendimentos e sensibilidades em torno do tráfico transatlântico também se inserem no contexto de internacionalização da memória do holocausto judeu, pensada como uma metáfora para diferentes traumas históricos (Huyssen, 2000), que leva a crescentes analogias com a ideia de crime contra a humanidade.

Desde então, alguns lugares da costa africana relacionados ao tráfico negreiro transatlântico e consagrados pelo RDE se transformaram em locais privilegiados para manifestações de arrependimento por parte de importantes personalidades religiosas e políticas, como o papa João Paulo II, os então presidentes Bill Clinton e Luiz Inácio Lula da Silva, e o então primeiro ministro Tony Blair. Nesses locais, eles pediram publicamente perdão pelo envolvimento pregresso de seus respectivos países com a escravidão negra. Por volta da mesma ocasião, os países africanos dirigiram pedidos de reparação material e simbólica à Europa pelos séculos de tráfico atlântico e de colonização (Araujo, 2007). Assim, os principais pontos do RDE tornam-se alvo de novas formas de entendimentos, ações e emoções que são historicamente construídas e que se articulam à persistência do racismo e às lutas pela sua superação.

Os anos 2000 representaram uma fase de amadurecimento para o projeto Rota do Escravo e a extensão da sua influência dentro e fora do Atlântico. Essa década marca um renascimento dos interesses diplomáticos, econômicos e políticos do Brasil junto à África, bem como uma valorização dos vínculos históricos e culturais entre ambas as realidades (Cicalo, 2014). É nesse contexto que devemos situar a visita do ex-presidente Lula à Ilha de Gorée e seu pedido oficial de perdão pelo envolvimento do Brasil no tráfico. Esses processos e seus desdobramentos precisavam amadurecer e decantar, fortalecendo um cenário político favorável à recente institucionalização da memória da diáspora africana, que não esconde interesses comerciais através do turismo étnico. 
Quando o Cais do Valongo foi desenterrado, os principais atores que giravam em torno da sua patrimonialização já estavam informados sobre o Rota do Escravo, o potencial turístico dos locais consagrados por esse projeto, as analogias com o holocausto judeu, as ideias de crime contra a humanidade, as emoções que despertam e, acima de tudo, a possibilidade latente do seu reconhecimento como patrimônio da humanidade. Os depoimentos emocionados de militantes negros, pesquisadores e representantes da prefeitura junto ao cais, bem como as públicas denúncias de discriminação racial, os pedidos de reparação e os eventos culturais e religiosos que começam a ser realizados no local, são influenciados pelo que ocorre internacionalmente e nos pontos emblemáticos do RDE. Assim, esses atores interpretam localmente as ideias, práticas e emoções desenvolvidas transnacionalmente em torno da escravidão negra, trazendo novas possibilidades de entendimento desse passado e novas formas de ação. Isso inclui também a integração do cais num circuito turístico e a possibilidade da sua transformação em patrimônio da humanidade. Portanto, é preciso levar em conta o contexto histórico e sociopolítico em que essa memória se constrói, pois ela se produz num plano localizado e historicamente situado, mas que se dá através de articulações transnacionais.

O sistema político e ético-jurídico de marco multicultural que se consolidou nas últimas décadas teria imprimido princípios norteadores aos principais atores envolvidos (o prefeito, o subsecretario de Patrimônio, os representantes do Comitê Rota do Escravo, os pesquisadores e os ativistas). Independentemente das divergências e dos diferenciais de poder, todos reconhecem o valor dos achados arqueológicos para o entendimento da memória afrodescendente. As transformações que vêm se efetuando nas últimas décadas desmontam o chamado mito da democracia racial e teriam sido dificilmente realizáveis poucos anos atrás. Dentro da nova perspectiva, pode-se construir uma crítica oficial ao Cais da Imperatriz, que simboliza a princesa "pisando sobre os escravos", cuja invisibilidade foi produzida "justamente" para conferir uma face mais nobre à história do país.

Um outro contexto fundamental para o entendimento da construção da memória da diáspora africana na região portuária é o do projeto Porto Maravilha, dito de requalificação. Ele se enquadra em tendências mais amplas de reformas urbanísticas que ocorrem em diversas cidades do mundo nas últimas décadas, tendo as transformações de Barcelona, voltadas para a realização das Olimpíadas de 1992, como principal referência. Neil Smith qualifica essa nova 
tendência como um processo de "gentrificação generalizada", caracterizado por um novo papel do Estado - nesse caso, da municipalidade -, que intensifica a sua parceria com o capital privado, resultando em parcerias público-privadas, e se submete cada vez mais às regras do mercado. Os projetos imobiliários se tornam a "peça central da economia produtiva [...], um fim em si, justificado pela criação de empregos, pela geração de impostos, pelo desenvolvimento do turismo e pela construção de grandes complexos culturais" (Smith, 2006, p. 79). Elas se diferenciam do fenômeno de gentrificação "espontânea”, fruto de iniciativas individuais de moradores e do capital privado rumo a bairros proletários centrais, que começou a ocorrer a partir dos anos 1960 (Glass, 1964). Alguns autores destacam nesses projetos o papel de "âncora" dos complexos culturais, construídos para atrair um público de maior poder aquisitivo que contribuiria para a renovação do bairro (Arantes, 2000; Kara-José, 2007).

De acordo com David Harvey (2005), os atuais processos de revitalização se vinculam ao fenômeno de empresariamento da gestão urbana, que ocorre nas últimas décadas. Nele, as cidades assumem um comportamento empresarial e subordinam seus fins à lógica do mercado, paralelamente ao processo de desindustrialização e de busca de novas formas de financiamento para as ações municipais. Nesses novos contextos, as tradições e histórias locais se convertem facilmente em capital simbólico e tornam-se atraentes mercadorias, na medida em que se transformam em marcos de distinção dos bairros e das cidades revitalizadas (Harvey, 2005).

Por trás dessas tendências generalizantes existem as especificidades dos contextos locais que trazem nuances e contrapontos. No caso do Rio de Janeiro, o empresariamento da sua gestão tem um marco importante na atuação do ex-prefeito Cesar Maia (Arantes, 2000; Vainer, 2000) e obtém ampla continuidade com o seu sucessor e atual prefeito, Eduardo Paes. Não por acaso, as reformas urbanísticas do porto ocorrem sob essas duas gestões. Alguns números nos informam sobre a grandiosidade do projeto Porto Maravilha: suas obras atingem uma superfície de 5 milhões de metros quadrados e previam um orçamento inicial de 7,6 bilhões de reais. Em veículos oficiais de divulgação do projeto, a prefeitura declara publicamente a sua intensão de transformar a região revitalizada numa nova imagem e num novo cartão-postal da cidade, atribuindo ao desenvolvimento do turismo um papel central (Pio, 2012). Os megaeventos internacionais que a cidade vem se propondo a abrigar também atendem a esses interesses. 
No entanto, num primeiro momento do Porto Maravilha, iniciado em 2010, o patrimônio afrodescendente da localidade não entrava na pauta. O projeto valorizava a criação de grandes complexos culturais voltados para um público internacional, consumidor de alta cultura e geralmente de fora do bairro, como o Museu de Arte do Rio, já inaugurado, e o Museu do Amanhã, em construção, destinado à ciência e à tecnologia. Foram necessárias as ações articuladas dos pesquisadores acadêmicos e dos militantes negros junto a representantes da municipalidade - descritas acima - para que as memórias da diáspora pudessem vir à tona e se institucionalizar, tendo como principal referência o Cais do Valongo.

Chegamos assim ao segundo entendimento do contexto: não apenas o do quadro de referências no qual se desenvolvem determinadas ações e representações, mas também aquele que, decorrente do primeiro, é produzido pelos atores e leva a transformações (Appadurai, 1996). Sugerimos que, através das suas ações, os três principais grupos de atores mencionados neste artigo produzem uma localidade, o Cais do Valongo, como um lugar de memória da diáspora africana. Ao fazê-lo, produzem também a si próprios, sujeitos de direito dessa memória e desse patrimônio. Para tanto, realizam um árduo trabalho de criação e manutenção do local, através de ritos que transformam a realidade. As declarações públicas sobre as memórias do cais, proferidas por militantes, pesquisadores e representantes da municipalidade; as cerimônias religiosas que nele ocorrem; as reuniões com delegações da Unesco; as visitas de personalidades representantes do movimento negro, do Estado e da Unesco; os decretos municipais e a colocação de placas, são todos acontecimentos que propiciam a construção dessa localidade. Através deles, são criados o monumento e patrimônio Cais do Valongo, os seus novos entendimentos e formas de gestão e os sujeitos que reivindicam seu pertencimento e herança.

\section{Considerações finais}

Neste artigo, tentamos observar as dinâmicas que favoreceram o enquadramento (Pollak, 1992) ou institucionalização de uma memória pública da diáspora africana no Rio de Janeiro. Tal como Appadurai (1996), acreditamos que esse processo só pode ser entendido levando-se em conta tanto o contexto 
que favorece a emergência das suas atuais ações e representações (como cais de desembarque de cativos africanos e lugar de memória da diáspora africana) quanto o que é recriado, refeito, transformado pelas ideias e pelos atos de seus principais atores envolvidos, ou seja, o seu próprio processo de patrimonialização. Ao problematizar a ideia de localidade e ao propor uma dimensão processual para a reflexão, Appadurai se abre para uma perspectiva que leva em conta a complexa coprodução de categorias e permite, no caso da nossa análise, a inclusão de pesquisadores acadêmicos, representantes do Estado e militantes negros.

No entanto, o processo de patrimonialização da diáspora africana não é plenamente consensual, mas sim permeado por conflitos. Por trás da convergência em torno da importância da institucionalização da memória do cais, temos diferentes posicionamentos e perspectivas. Para as lideranças do movimento negro envolvidas, o cais parece simbolizar a sua ancestralidade e as suas lutas por reconhecimento e visibilidade. Junto com muitos pesquisadores implicados no processo, defendem a implementação de um turismo étnico ou de memória que leve à reflexão sobre o passado escravocrata e a discriminação racial. Já para os representantes da prefeitura mais diretamente implicados, o sítio parece atender sobretudo às expectativas de desenvolvimento turístico da região, que acreditam contribuir positivamente para o êxito do ambicioso projeto de revitalização, atraindo um público de maior poder aquisitivo e valorizando uma localidade ainda bastante estigmatizada. Assim, ainda que com entendimentos diferenciados, ambos os grupos de atores convergem em torno da promoção da memória da diáspora africana e da sua patrimonialização e monumentalização: chegam a uma unanimidade negociada.

Acreditamos que a patrimonialização do Cais do Valongo só pode surgir no atual contexto que conjuga um gradual amadurecimento da denúncia da discriminação racial na sociedade brasileira com as novas formas de gestão urbana, responsáveis por grandes projetos de revitalização. Por isso o cais não pôde ser desenterrado em 2005, mas o foi em 2011. É quando ambas as perspectivas chegam à região portuária que a memória do tráfico negreiro ganha força política e se difunde amplamente, graças à atuação dos principais grupos de atores envolvidos. Através de suas ações convergentes, consolidam a memória da diáspora africana e incluem-na no projeto Porto Maravilha de revitalização. 


\section{Referências}

APPADURAI, A. Modernity at large: cultural dimensions of globalization. Minneapolis: University of Minnesota Press, 1996.

ARANTES, O. Uma estratégia fatal: a cultura nas novas gestões urbanas. In: ARANTES, O. et al. (Org.). A cidade do pensamento único. Petrópolis: Vozes, 2000. p. 12-74.

ARAUJO, A. L. Mémoires de l'esclavage et de la traite des esclaves dans l'Atlantique Sud: enjeux de la patrimonialisation au Brésil et au Bénin. 2007. Tese (Doutorado em História)-Université Laval, Québec, 2007.

ARAUJO, A. L. Caminhos atlânticos: memória, patrimônio e representações da escravidão na Rota dos Escravos. Varia Historia, Belo Horizonte, v. 25, n. 41, p. 129-148, jan./jun. 2009.

ARAUJO, A. L. Public memory of slavery: victims and perpetrators in the South Atlantic. New York: Cambria Press, 2010.

ARRUTI, J. M. Mocambo: antropologia e história do processo de formação quilombola. Bauru: EDUSC: ANPOCS, 2006.

BLAKEY, M. Leprojet de cimetière africain: un paradigme pour la coopération? Museum International, Oxford, v. 62, n. 245-246, p. 64-71, 2010.

BRASIL. Lei $n^{\circ}$ 10.639, de 9 de janeiro de 2003. Altera a Lei no 9.394, de 20 de dezembro de 1996, que estabelece as diretrizes e bases da educação nacional, para incluir no currículo oficial da Rede de Ensino a obrigatoriedade da temática "História e Cultura Afro-Brasileira", e dá outras providências. Brasília, 2003. Disponível em: <http://www.planalto.gov.br/ccivil_03/ leis/2003/l10.639.htm>. Acesso em: 1 jul. 2014.

CARTA de recomendações do Valongo. Rio de Janeiro, 2012. Carta elaborada pelo Grupo de Trabalho Curatorial do Circuito da Herança Africana, divulgada em audiência pública em 26 de junho de 2012. 
CHIVALLON, C. Bristol and the eruption of memory: making the slavetrading past visible. Social \& Cultural Geography, London, v. 2, n. 3, p. 347363, 2001.

CICALO, A. Urban encounters: affirmative action and black identities in Brazil. New York: Palgrave MacMillan, 2012.

CICALO, A. A voice for the past: making "public” slavery heritage in Rio de Janeiro. International Journal of Tourism Anthropology, Geneva, v. 3, n. 2, p. 170-183, 2013.

CICALO, A. From racial mixture to black nation: racialising discourses in Brazil’s African affairs. Bulletin of Latin American Research, Oxford, v. 33, n. 1, p. 16-30, 2014.

CLIFFORD, J. Diasporas. Cultural Anthropology, Washington, v. 9, n. 3, p. 302-338, 1994.

COSTA, F. C. da. Morro da Conceição: uma etnografia da sociabilidade e do conflito numa metrópole brasileira. 2010. Dissertação (Mestrado em Antropologia Social)-Centro de Educação e Ciências Humanas, Universidade Federal de São Carlos, São Carlos, 2010.

DAFLON, R. Cariocas e turistas poderão ver de arquibancadas como eram os Cais da Imperatriz e do Valongo, descobertos em escavações. O Globo, 10 mar. 2011. Disponível em: <http://oglobo.globo.com/rio/cariocasturistas-poderao-ver-de-arquibancadas-como-eram-os-cais-da-imperatriz-dovalongo-descobertos-em-escavacoes-2813539>. Acesso em: 1 jul. 2014.

FABRE, D. Introduction: habiter les monuments. In: FABRE, D.; IUSO, A. Les monuments sont habités. Paris: Editions de la Maison des Sciences de l’Homme, 2009. p. 17-54.

GILROY, P. O Atlântico Negro: modernidade e dupla consciência. São Paulo: Editora 34, 2001.

GLASS, R. London: aspects of change. London: Center for Urban Studies: MacGibbon and Kee, 1964. 
GONÇALVES, J. R. Antropologia dos objetos: coleções, museus e patrimônios. Rio de Janeiro: Iphan, 2007. (Coleção Museu, Memória e Cidadania).

GUIMARÃES, R. S. A utopia da Pequena África: os espaços do patrimônio na Zona Portuária carioca. 2011. Tese (Doutorado em Sociologia e Antropologia)-Instituto de Filosofia e Ciências Sociais, Universidade Federal do Rio de Janeiro, Rio de Janeiro, 2011.

HANDLER, R. On social discontinuity: nationalism and cultural objetification in Quebec. Current Anthropology, Chicago, v. 25, n. 1, p. 55-71, 1984.

HARVEY, D. A produção capitalista do espaço. São Paulo: Annablume, 2005.

HONORATO, C. de P. Valongo: o mercado de escravos do Rio de Janeiro, 1758 a 1831. 2008. Dissertação (Mestrado em História)-Instituto de Ciências Humanas e Filosofia, Universidade Federal Fluminense, Niterói, 2008.

HUYSSEN, A. Seduzidos pela memória: arquitetura, monumentos, mídia. Rio de Janeiro: Aeroplano, 2000.

KARA-JOSÉ, B. Políticas culturais e negócios urbanos (1975-2000). São Paulo: Annablume: Fapesp, 2007.

LANDRY, T. Touring the slave route: inaccurate authenticities in Bénin, West Africa. In: SILVERMAN, H. (Ed.). Contested cultural heritage. New York: Springer, 2011. p. 205-231.

MAIO, M. C. Cientificismo e antirracismo no Pós-2a Guerra Mundial: uma análise das primeiras Declarações sobre Raça da Unesco. In: MAIO, M. C.; SANTOS, R. B. Raça como questão: história, ciência e identidades no Brasil. Rio de Janeiro: Fiocruz, 2010. p. 147-170.

MATTOS, H.; ABREU, M.; GURAN, M. (Org.). Inventário dos lugares de memória do tráfico atlântico de escravos e da história dos africanos escravizados no Brasil. Niterói: Universidade Federal Fluminense, 2014.

NIMAKO, K.; WILLEMSEN, G. The Dutch Atlantic: slavery, abolition and emancipation. New York: Pluto Press, 2011. 
PEREIRA, J. C. M. da S. À flor da terra: o Cemitério dos Pretos Novos no Rio de Janeiro. Rio de Janeiro: Garamond: Iphan, 2007.

PIO, L. G. Ações culturais e comunicação no projeto Porto Maravilha. In: ENCONTRO DE CIÊNCIAS SOCIAIS DO NORTE E NORDESTE E PRÉALAS BRASIL, 15., 2012, Teresina. Anais... Teresina: Universidade Federal do Piauí, 2012. Disponível em: <http://www.sinteseeventos.com.br/ciso/ anaisxvciso/resumos/GT07-12.pdf>. Acesso em: 1 jul. 2014.

POLLAK, M. Memória e identidade social. Estudos Históricos, Rio de Janeiro, v. 5, n. 10, p. 200-212, 1992.

PROPOSTA de carta aberta de reivindicações referentes ao Cais do Valongo e à Pequena África. Rio de Janeiro, 2011. Elaborada por lideranças do movimento negro em 24 de junho de 2011.

RIO DE JANEIRO (Município). Decreto $n^{\circ}$ 24.088, de 5 de abril de 2004. Cria o Portal dos Pretos Novos. Rio de Janeiro: Câmara Municipal, 2004. Disponível em: <http://cm-rio-de-janeiro.jusbrasil.com.br/legislacao/917198/ decreto-24088-04>. Acesso em: 1 jul. 2014.

RIO DE JANEIRO (Município). Decreto $n^{0}$ 34.802, de 29 de novembro de 2011. Dispõe sobre a inclusão do Projeto de Implantação e Manutenção do “Parque Olímpico Rio 2016” no Programa Municipal de Parcerias PúblicoPrivadas - PROPAR-RIO. Diário Oficial do Município do Rio de Janeiro, Rio de Janeiro, ano 25, n. 117, p. 1, 30 nov. 2011.

SAFRAN, W. Diasporas in modern societies: myths of homeland and return. Diaspora, Toronto, v. 1, n. 1, p. 83-99, 1991.

SCHRAMM, K. Senses of authenticity: chieftaincy and the politics of heritage in Ghana. Etnofoor, Amsterdam, v. 17, n. 1-2, p. 156-177, 2004.

SEMINÁRIO Internacional "Herança, identidade, educação e cultura: gestão dos sítios e lugares de memória ligados ao tráfico negreiro e à escravidão": relatoria: sessão de abertura. Brasília: Fundação Cultural Palmares: Organização das Nações Unidas para a Educação, a Ciência e a Cultura, 2012. Disponível em: <http://www.palmares.gov.br/rotadoescravo/wp-content/ uploads/2012/08/sessao-de-abertura.pdf> . Acesso em: 1 jul. 2014. 
SILVERMAN, H. Contested cultural heritage: a selective historiography. In: SILVERMAN, H. (Ed.). Contested Cultural Heritage. New York: Springer, 2011. p. 1-50.

SINGLETON, T.; TORRES DE SOUZA, M. A. Archaeologies of the African diaspora: Brazil, Cuba, United States. In: MAJEWSKI, T.; GAIMSTER, D. (Ed.). International handbook for historical archaeology. New York: Springer, 2009. p. 449-469.

SMITH, N. A gentrificação generalizada: de uma anomalia local à "regeneração" urbana como estratégia global. In: BIDOU-ZACHARIASEN, C. (Org.). De volta à cidade: dos processos de gentrificação às políticas de “revitalização” dos centros urbanos. São Paulo: Annablume, 2006. p. 59-87.

SOARES, C. E. L. A negregada instituição: os capoeiras no Rio de Janeiro. Rio de Janeiro: Divisão de Editoração da Secretaria Municipal de Cultura, 1994.

SOARES, C. E. L. Zungu: rumor de muitas vozes. Rio de Janeiro: Arquivo Público do Estado do Rio de Janeiro, 1998.

SOARES, C. E. L. A Pequena África: um portal do Atlântico. Rio de Janeiro: Ceap, 2011.

TAVARES, R. Cemitério dos Pretos Novos, Rio de Janeiro, século XIX: uma tentativa de delimitação espacial. 2012. Dissertação (Mestrado em Arqueologia)-Museu Nacional, Universidade Federal do Rio de Janeiro, Rio de Janeiro, 2012.

TROUILLOT, M.-R. Silencing the past: the power and production of history. Boston: Beacon Press, 1995.

VAINER, C. Os liberais também fazem planejamento urbano? Glosas ao "Plano Estratégico da Cidade do Rio de Janeiro". In: ARANTES, O. et al. (Org.). A cidade do pensamento único. Petrópolis: Vozes, 2000. p. 105-120. 
VASSALLO, S. P. Desenterrando memórias: patrimônios afrodescendentes em disputa na Zona Portuária do Rio de Janeiro. In: SOUZA, R. (Org.). Sociedade em perspectiva: cultura, conflito, identidade. Rio de Janeiro: Gramma, 2012. p. 157-187.

VASSALLO, S. P. Culturas em disputa: a criação do Programa Porto Maravilha Cultural no projeto de revitalização da região portuária do Rio de Janeiro. In: SANTOS, M.; PONTES JR., G.; CASTRO, M. Diálogos interdisciplinares: literatura e políticas culturais. Rio de Janeiro: EDUERJ, 2014. p. 57-81. 